\title{
Prunetin Inhibits Nitric Oxide Activity, Proliferation and Induces Apoptosis in Urinary Bladder Cancer Cells (RT-4) Through the Enhancement of Apoptotic Pathway via CASP3 and TNF- $a$ Genes That Are Involved
}

Cinel KOKSAL KARAYILDIRIM ( $\nabla$ cinel.koksal@ege.edu.tr)

Ege Universitesi https://orcid.org/0000-0002-8431-1230

Ayse NALBANTSOY

Ege University: Ege Universitesi

Nefise Ulku KARABAY YAVASOGLU

Ege University: Ege Universitesi

Research Article

Keywords: Prunetin, Urinary bladder cancer, Apoptosis, Gene expression, iNOS activity.

Posted Date: May 7th, 2021

DOl: https://doi.org/10.21203/rs.3.rs-445738/v1

License: (1) (i) This work is licensed under a Creative Commons Attribution 4.0 International License.

Read Full License 


\section{Abstract}

Urinary bladder cancer is considered one of the most prevalent malignant tumors worldwide. Complementary and integrative approaches for the treatment of bladder cancer, such as the intake of isoflavonoid phytoestrogens, are increasingly explored due to the risk of mortality and long-term morbidity associated with surgical procedures. The biological effects of prunetin, one of the less-studied phytoestrogens, have not yet been examined in this respect. Therefore, this study aimed to explore the efficacy of prunetin on urinary bladder cancer cells (RT-4).

Cytotoxicity, nitric oxide synthase activity, apoptotic gene expression and cell cycle assays were performed to determine the biological effect of prunetin exposure on cellular toxicity, cell cycle progression and the expresions of selected apoptosis-related genes. The results suggested that prunetin has cytotoxic effects on RT-4 cells at $21.11 \mu \mathrm{g} / \mathrm{mL}$. Flow cytometry analysis showed that prunetin induced apoptosis and cell cycle arrested in $\mathrm{G}_{0} / \mathrm{G}_{1}$ phase. Prunetin exposure was associated with increases in CASP3 and TNF- $a$ gene expression in RT-4 cells at doses of $21.11 \mu \mathrm{g} / \mathrm{mL}$ and $42.22 \mu \mathrm{g} / \mathrm{mL}$. Strong nitric oxide inhibition was determined with $\mathrm{IC}_{50}$ of $5.18 \mu \mathrm{g} / \mathrm{mL}$ under macrophage mediated inflammatory circumstances.

Based on the experimental data, it is reasonable to conclude that prunetin possesses anti-cancer properties and may be a candidate compound for the prevention of urinary bladder cancer. This is the first study that evaluated prunetin for its in vitro antitumor activities, clarified its possible apoptotic molecular mechanism and provided novel insights into its anti-inflammatory nature and effects on the expression of related key genes.

\section{Introduction}

Cancer encompasses a large number of diseases that are all charactericterized by abnormal and uncontrollable cell growth, disintegration of normal body tissue, dissemination into other tissues, formation of belign tumors, and metastasis. It is thought by physicians that 20 million new cancer cases will be diagnosed throughout the world every year. Therefore, this disease is a global burden which is expected to increase [1]. One of the most diagnosed types of cancer is urine bladder cancer which affects more than 570,000 people worldwide each year and based on current data, it has been established that 1.7 million people are afflicted by urine bladder cancer [2]. Thus, urine bladder cancer affects many people worldwide each year and is often diagnosed late. Bladder cancer therapy depends on how deeply the tumor has invaded the bladder tissue and can be classified as non-invasive or muscle invasive. However, radiotherapy, targeted therapy, chemotherapy or immunotherapy are not sufficient to increase survival rates and also have many side effects which lower the quality of life.

The therapeutic approaches currently available for the treatment of cancer should be supported by integrative medicine. Complementary and alternative approaches in cancer treatment have recently become acceptable approaches aimed at control of tumoral molecular mechanisms, apoptotic pathways, 
cytotoxic and antiangiogenic efficacies [3]. Plants are natural sources for phytotherapy and have an important role in preparation of herbal formulations and cancer treatment [4]. The major active components of plant based fomulations are polyphenolic compounds such as flavonoids, isoflavonoids and neoflavonoids. These molecules regulate molecular mechanisms, cell proliferation, apoptotic pathways and tumor angiogenesis in different type of cancers [5]. Phytoestrogens are derived from plant flavonoids with estrogenic properties. The major group of phytoestrogens is isoflavones which include many well-studied compounds such as daidzein, genistein, formononetin and biochanin A [6, 7]. The potential effects of phytoestrogens on health have attracted attention especially as it was observed that Asian people who consume soy and soy products, have lower incidences of breast and prostate cancer, osteaoporosis and cardiovascular diseases when compared to individuals in western societies [8, 9]. Epidemiological studies have indicated that phytoestrogen supplements have protective and therapeutic effects under certain dose and exposure conditions [10]. Isoflavonoid phytoestrogens have chemopreventive activity to regulate platelet aggregation, angiogenesis, cell differentiation and wound healing processes $[11,12]$. Previous studies have proved the role of isoflavones in cell transformation and their metastatic, apoptotic and anti-inflammatory effects [13]. One phytoestrogenic compound is prunetin, an O-methylated isoflavone found in Trifolium pratense, Pisum sativum and Prunus avium [14]. However, limited studies have focused on the biological activities of prunetin with the exception of its antiinflammatory and anti-obesity effects [15]. Genistein suppresses metastasis, migration and modulates tumor microenvironment while daidzein has been utilized in cancer therapy to regulate the metabolism of estrogen in breast cancer [16]. Considering the structural similarity between these isoflavones, it is possible that prunetin has a wide range of biological activity. Therefore, to fill this gap in knowledge, the anti-tumor effect of prunetin on cancer cell lines was investigated. Moreover, the expressions of genes associated with the apoptotic mechanisms of prunetin were evaluated using RT-4 cells. In addition, nitric oxide synthase activity was measured to understand the tissue protective or damaging effects of prunetin treatment. Based on currently available evidence, this is the first study in which prunetin has been shown to have the potential to induce apoptosis and to be a preventive anti-cancer agent.

\section{Materials And Methods}

\subsection{Chemicals and kits}

Prunetin (CAS Number: 552-59-0, $\geq 98.0 \%$ TLC) was obtained from Sigma-Aldrich. Annexin V-FITC Apoptosis Detection Kit I with 1x Binding Buffer and Propidium lodide (PI) were purchased from BioVision Inc. Human inducible nitric oxide synthase (iNOS) ELISA Kit was obtained from MyBioSource, Inc., USA. Fetal Bovine Serum (FBS, F2442) was purchased form Sigma-Aldrich. All of the chemicals were of analytical grade.

\subsection{Methods}

\subsection{In vitro Cytotoxicity test}


Breast cancer (MDA-MB 231, HTB-26 $6^{\text {TM }}$ MCF-7, HTB-22 ${ }^{\text {TM }}$ ), cervical cancer (HeLa, CCL-2 ${ }^{\text {TM }}$ ), alveolar adenocarcinoma (A549, CCL-185 $5^{\mathrm{TM}}$ ), prostate cancer (PC3, CRL-1435 $5^{\mathrm{TM}}$ ), urinary bladder cancer (RT-4, HTB$2^{\text {TM }}$ ), colon cancer (Caco-2 HTB-37 ${ }^{\text {TM }}$ ) and embryonic kidney cells (HEK293, CRL-1573 ${ }^{\text {TM }}$ as noncancerous cell line) were obtanied from the American Type Culture Collection. Cells were maintained in different media (DMEM, DMEM/F12, RPMI-Gibco, UK) supplemented with $4 \%$ heat inactivated FBS (Sigma-Aldrich, F2442), $1 \%$ L-glutamine (Biochrome, Germany) and $1 \%$ gentamycine (Invitrogen) at $37^{\circ} \mathrm{C}$ in $5 \% \mathrm{CO}$. Doxorubicin was used individually as positive control ( $40 \mu \mathrm{L}$ in each well).

\subsubsection{Cell viability assay and determination of $\mathrm{IC}_{50}$}

The in vitro cytotoxic effect of prunetin was assessed based on metabolic cell viability procedure. Mitochondrial reductase activity and proliferation of cells were determined according to a modified MTT assay [17]. Cell lines were cultivated at the density of $1 \times 10^{4}$ cells $/ \mathrm{mL}$ in V-bottom 96 well plates maintained overnight at $37^{\circ} \mathrm{C}$. After the cultured cells were treated with $0.5,5,50 \mu \mathrm{g} / \mathrm{mL}$ of prunetin for $48 \mathrm{~h}$ at $37^{\circ} \mathrm{C}, 150 \mu \mathrm{L} \mathrm{DMSO}(5 \mathrm{mg} / \mathrm{mL})$ solution/well was added and incubated at $37^{\circ} \mathrm{C}$ for $4 \mathrm{~h}$ to dissolve formazan crystals and produce a purple solution that indicates viable cells. Untreated controls were used as comparison of growth inhibition to determine the prunetin concentration that inhibited cell growth by $50 \%\left(\mathrm{IC}_{50}\right)$. The optical density was measured with UV spectroscopic analysis at $560 \mathrm{~nm}$ and the percentage of viable cells was calculated. The experiment was done in triplicats and the percentage of cell survival was calculated as follows:

The GraphPad PRISM (version 7) programme was used to calculate the $\mathrm{IC}_{50}$ values which were assessed at $\pm 95 \%$ confidence intervals.

\subsection{Apoptotic Assay-Annexin V-FITC/ PI double staining}

Annexin V-Fluorescein isothiocyanate conjugate (FITC) and propidium iodide (PI) staining was used to quantify the apoptotic rate of RT-4 and HEK-293 cells according to the manufacturer's directions. Briefly, $5 \times 10^{5}$ cells were exposed to different concentrations of prunetin (based on the calculated $\mathrm{IC}_{50}$ values) in 6-well plates for $48 \mathrm{~h}$. Then, cells were stained with Annexin V-FITC (5 uL-15 min) and PI (10 uL-5 min) in the dark condition at room temperature. Cellular apoptotic rate was measured using a flow cytometer (BD Biosciences, US) [18].

\subsection{Real-time PCR assay}

The doses of prunetin used to assess apopotic effects on RT-4 and HEK-293 cells were chosen based on the results of cell viability assays and $\mathrm{IC}_{50}$ values. Total RNA was isolated from RT-4 and HEK-293 cells using the Qiagen RNeasy kit according to the manufacturer's instructions. Residual genomic DNA was removed from total RNA with DNAsel. Then, cDNA was subsequently synthesized from the total RNA using a EvoScript Universal cDNA Master Kit. The expression of CASP3 and TNF- $a$ mRNA were assessed with Power SYBR Green Master Mix (Applied Biosystems) with RT-PCR assays (Applied Biosystems StepOne Plus-System). As an internal control, $\beta$-actin was used to normalize the level of CASP3 and TNF- 
$a$ mRNA. Primer sequences are listed in Table 1. As a reference point, non-treated cells were chosen and calculation of relative expression levels for genes were conducted with respect to this reference value (set to 1). StepOne Plus software was used for qRT-PCR data analyses.

\subsection{Nitric oxide synthase activity assay}

RAW 264.7 cells (ATCC ${ }^{\circledR}$ TIB-71 $1^{\text {TM }}$ ) were cultered $\left(1 \times 10^{5}\right.$ cells) in LPS and phenol red free RPMI 1640 medium with $10 \%$ FBS then incubated for 24 hours. After inducing with $1 \mu \mathrm{g} / \mathrm{mL}$ LPS, 5, 10 and 50 $\mu \mathrm{g} / \mathrm{mL}$ concentrations of prunetin were added and incubated under the same conditions for another $24 \mathrm{~h}$. Dose curves were used to calculate $\mathrm{IC}_{50}$ values and positive control was parthenolide. All tests were conducted in triplicate and Griess reagent was used to determine the amount of $\mathrm{NO}_{2}{ }^{-}$in supernatants at $540 \mathrm{~nm}$ absorbance [19].

\subsection{Statistical analysis}

Statistical data are presented as means \pm SD from three independent experiments and were analyzed using Student's t-test or one-way ANOVA to determine statistically significant differences at $P<0.05$.

\section{Results}

\subsection{In vitro Cytotoxic Activity}

In vitro cytotoxic activity and percentage of dead cells of prunetin-treated MDA-MB 231, HeLa, A549, PC3, RT-4, Caco-2, MCF-7, HEK293 cells were examined. Different IC $_{50}$ values and cell viabilities after 48 hours of prunetin treatment were observed depending on the origin of human tumor cell lines. Prunetin exhibited the strongest cytotoxic activity with $\mathrm{IC}_{50} 21.11 \mu \mathrm{g} / \mathrm{mL}$ against RT-4 cells. Additionally, a marked growth inhibitory effect of prunetin on Caco-2 and MCF-7 cells was shown in a dose dependent manner with $\mathrm{IC}_{50} 24.16$ and $27.18 \mu \mathrm{g} / \mathrm{mL}$, respectively. Prunetin at the $50 \mu \mathrm{g} / \mathrm{mL}$ concentration showed a slight decrease in a cellular viability of the PC3, A549, HeLa and. MDA-MB 231 cells. Evaluation of the results revealed that prunetin has strong cytotoxic effect for urinary bladder cancer cell was chosen for target cell for further studies. The results of cytotoxicity assays are summarized in Table 2 and Fig. 1.

\subsection{Apoptosis assay}

The apoptosis rates of RT-4 and HEK-293 cells were quantified and evaluated by combined staining of Annexin V-FITC and PI using an Apoptosis Detection Kit. Cells without prunetin treatment were considered as a control group. It was demostrated that prunetin had no significant effects on induction of apoptosis of HEK-293 cells at 27.03 and $54.06 \mu \mathrm{g} / \mathrm{mL}$. However, a slight, early apopotosis effect was detected at 21.11 and $42.22 \mu \mathrm{g} / \mathrm{mL}$ prunetin on RT-4 cells. (Fig. 2A, 3A). It was demostrated that effects of prunetin exposure on cell cycle progression. Cells were approximately equally distributed among the M1 phases of the cell cycle (Figs. 2B, 3B).

\subsection{Effects on mRNA level of apoptotic genes}


In this study, change in gene expression (fold change) and biological significance were examined in cell lines treated with prunetin and compared to the control group (untreated cells). Prunetin was applied to both RT-4 and HEK-293 cell lines at concentrations of $10.16 \mu \mathrm{g} / \mathrm{mL}, 21.11 \mu \mathrm{g} / \mathrm{mL}$ and $42.22 \mu \mathrm{g} / \mathrm{mL}$. The expression of CASP-3 and TNF-a genes in cell line RT-4 increased significantly at concentrations of 21.11 $\mu \mathrm{g} / \mathrm{mL}$ and $42.22 \mu \mathrm{g} / \mathrm{mL}$ as compared to the control. The increase in activity of the caspase- 3 gene was especially noticeable and was shown to be more than 2 times that of the control. A statistically significant change was not detected at other concentrations and in HEK-293 compared to the control.

\subsection{Nitric oxide synthase activity result}

In this study, the anti-inflammatory effects of prunetin on nitric oxide synthesis in LPS induced RAW 264.7 macrophage cells have been researched. According to a method based on the Griess reaction, inhibition of NO levels caused of prunetin in RAW 264.7 macrophage cells was demonstrated and the $\mathrm{IC}_{50}$ value of prunetin was calculated as $5.18 \mu \mathrm{g} / \mathrm{mL}$. Doxorubicin which is the positive control, had $\mathrm{IC}_{50}$ of $6.26 \mu \mathrm{g} / \mathrm{mL}$. The prunetin had decreased NO production by $65 \%$ at $50 \mathrm{ug} / \mathrm{mL}$ concentration. Additionally, the cytotoxic effect of prunetin on macrophage cells was not detected (Table 3 ).

\section{Discussion}

It is well known that the incidence of cancer will increase to over 20 million new cases annually within the next decades [3]. Urinary bladder cancer is among the most especially lethal malignancies affecting people all over the world. Drug-resistance remains one of the major challenges in treatment of urinary bladder cancer. Unfortunately, conventional therapy methods for cancer disease and metastasic turmors are not sufficient. Currently, integrative advance in cancer treatment have been developed beyond the stimulation of cell cycle arrest, induction of cytotoxicity, halting of metastasis, modulation of inflammatory response and regulation of apoptotic pathways. Worldwide, $70-80 \%$ of people prefer to use natural compounds as an alternative and complementary approach to disease treatment [20]. Among these alternatives, bioactive secondary metabolites such as phenolics and flavonoids produced by plants have important roles due to their various pharmacological activities. Isoflavones are one of the most abundant types of flavonoids and many such compounds have displayed various biological efficacies [21]. Isoflavonoid phytoestrogens have similar structures and activities as estrogens such as induction of estrogen receptors and play an important role in modulating the expression of many genes related to hormone response. Recently, there has been growing interest in exploring the effects of isoflavones as a chemopreventive agent to prevent the progression of cancer, improve drug efficacy and attenuate toxicity $[22,23]$. The growing importance of naturally occurring phytochemicals such as daidzein, genistein, formononetin, and biochanin-A is due to their beneficial health effects in preventing and treating diseases [24]. However, there is insufficient scientific evidence verifying the effectiveness and safety of many polyphenols [25]. It has been reported that estrogenic isoflavones have marked pharmacological effects against diverse pathological states $[10,26]$. For instance, genistein and daidzein are an important isoflavonoid that have displayed anti-tumoral efficacy against a wide range of cancer types [27]. Prunetin belongs to the tremendous isoflavone family, and could be a remarkable candidate with preventative, 
therapeutic and complementary effects as an alternative treatment for cancer especially urinary bladder cancer. However, the anticancer efficacy of prunetin has not yet been reported. As a result, it is important to understand the possible molecular mechanism responsible and target cancer type for prunetin. In the literature, it has been indicated that many isoflavones inhibit cell proliferation. To be used as an effective anti-cancer compound, plant-based substances should be inhibited proliferation of cancer cells without causing intense damage. For this reason, different types of cancer cell lines were used to assess the efficacy of prunetin in cytotoxicity assay. Prunetin was evaluated for its in vitro anti-cancer activities towards several human carcinomas and showed significant cytotoxic effects in a concentration and exposure time-dependent manner, agreeing with previous studies indicating that phytoestrogen isoflavones may be effective anticancer compounds $[28,29]$. The study successfully demonstrated that exposure of RT-4 cell to prunetin significantly inhibits cell viability. In addition, prunetin demonstrated significant anti-proliferative effects on MCF-7, Caco-2 and A-549 cells, reducing their viability. These findings are in agreement with the in vitro results of this study, which demonstrated that high concentration of prunetin caused cytotoxicity similar to those caused by other isoflavones [30, 31, 32]. Our results have shown that prunetin's anti-tumorigenic effects are mediated by inhibiting cellular growth of the target cell line RT-4 for further studies.

Apoptosis is a programmed cell death that occurs by normal physiological processes and involves cell shrinkage and the loss of membrane integrity. It allows Annexin $V$ staining becomes detectable and then, as the cells become permeable, PI which is a nucleic acids-specific stain, gains access to the DNA [33]. Therefore, externalisation and distinguishing of phosphatidylserine on the outer membranes of apoptotic cells can be observed by Annexin V-FITC/PI stain. This technique allows distinguishing of cells at different stages of apoptosis and necrosis. Considering this, Annexin V-FITC/PI analysis was performed to determine apoptosis and the results indicated a slight, early apoptosis effect induced in RT-4 cells treated with prunetin. According to discrimination of apoptotic and necrotic cell death, the cells which were exposed to different concentrations of prunetin and the time-dependent study were evaluated using flow cytometry. The results provided evidence that prunetin had apoptotic effects on urinary bladder cancer cells at 21.11 and $42.22 \mu \mathrm{g} / \mathrm{mL}$. The prunetin treatment was accompanied by a delay in the $\mathrm{G}_{1}$ phase of the cell cycle after 48 hours' treatment. Cells were halted during chromosome duplication and could not continue to grow and prepare for mitosis. As a result of prunetin exposure, cell proliferation of RT-4 cells was inhibited by interrupting the cell cycle in either the $G_{0} / G_{1}$ phase, which in turn, may activate the apoptotic pathway. These studies were supported by other well-studied phytoestrogen isoflavonoids which are mostly Annexin V-PI positive. Genistein was shown to cause apoptotic cell death in MCF-7 cells at $0.15 \mathrm{mM}$ and was accompanied by cell cycle delay in the $G_{2} / M$ phase [34]. Moreover, it was shown that in pancreatic ductal epithelial cells ( $\mathrm{H6C7}$ ), genistein stimulated morphological changes and caused arrest in the $\mathrm{G}_{0} / \mathrm{G}_{1}$ phase [35]. Daidzein, which is the most commonly known phytoestrogen, activated the apoptotic Fas/FasL-initiated pathway in cancer cells [36]. Biochanin A is another apoptotic inducer that plays a key role in MG-63 and U2O cells by triggering activation of the intrinsic mitochondrial pathway, pro-caspase 9 and pro-caspase 3 [31]. Prunetin triggered $G_{0} / G_{1}$ cell cycle arrest on RT-4 cells and induced apoptosis. It was also shown that CASP-3 and TNF-a gene expression significantly increased compared 
to the control 48 hours' post-treatment. Prunetin markedly escalated caspase-mediated apoptosis via the transformation of the apoptosome complex which, in turn, activates caspase 3 and led to apoptosis of RT-4 cells. Many phytoestrogen isoflavones prevent proliferation in cancer cells through cell cycle arrest by activation of caspase- 9 and 3 [11]. Prunetin also enhanced endogen pyrogen TNF-a gene expression in RT-4 cells. All of these findings show that the anticancer activities of prunetin are achieved by modulation of the apoptotic mechanisms and gene regulation.

TNF- $a$ is an inflammatory cytokine produced by macrophages during acute inflammation and is responsible for a diverse range of signalling events within cells, leading to necrosis or apoptosis [37]. This protein is also important for resistance to infection and cancers. Its expression mediates various cell functions such as stimulation of nitric oxide inhibition under oxidative stress conditions or inflammation. Therefore, the effect of prunetin on NO production of macrophages cell after LPS stimulation was examined in this study. Previous studies demostrated that isoflavones have estrogenic activity and can modulate iNOS mRNA production [38, 39]. In our study, the results proved that the enhancing effects of prunetin aroused through the ERa pathway in cells, induces iNOS expression and then regulated NO production. The $\mathrm{IC}_{50}$ value on RAW 264.7 cells showed that prunetin had non-cytotoxic effect for the iNOS-effective dose. Prunetin had possessed significant inhibitory activity against NO production as $65 \%$ at $50 \mu \mathrm{g} / \mathrm{mL}$. Researchers had associated the promising results against inflammation stressors with the isflavonoids content of the plants [40]. Likewise, daidzein and genistein, two very important secondary metabolites with estrogenic properties, exert a similar effect on estrogen receptors, decreased NO production. This decrease is caused by the decrease of iNOS protein expression [41].

Our study presents the first evidence that the isoflavone prunetin is a NO inhibitor and enhances apoptosis via regulation of $C A S P 3$ and TNF-a genes. Moreover, the results indicate that prunetin arrests the cell cycle, suppresses the invasive potential of cancer cells and may, therefore, be beneficial in the management of urinary bladder cancer. In conclusion, the present study provides perspective and evidence that prunetin could serve as a novel therapeutic strategy for preventing and treating urinary bladder cancer.

\section{Declarations}

\section{Funding}

This work was supported by The Scientific and Technological Research Council of Turkey (TUBITAK, Grant no: 119Z028).

\section{Data availability}

All authors make sure that all data and materials support the published claims and comply with feld standards.

\section{Acknowledgments}


The authors would like to thank Prof. Dr. Anne FRARY from Izmir Institute of Technology, Izmir, Turkey, for providing kind advice during the drafting of this manuscript.

\section{Author contributions}

ÇKK performed the project, research design all experiments and wrote the manuscript. AN prepared the cells for cell culture and supported the cytotoxcity test. NUKY helped to data interpretation and statistical analysis

\section{Compliance with ethical standards}

\section{Conflict of interest}

The authors declare they have no conficts/competing of interest.

\section{Ethical approval}

Ethical approval was not required because the experiments utilized in vitro cell culture tecniques.

\section{Consent to participate}

The authors are agreed to publish this manuscript.

\section{References}

1. Stewart W, Wild C. (Eds.), World Cancer Report (2014). Lyon: International Agency for Research on Cancer, ISBN 978-92-832-0429-9.

2. Global Cancer Observatory (2021) WHO Bladder Cancer Factsheet, Access date: 13.February.2021.

3. Apaya KM, Chang TM. Shyur FL (2016) Phytomedicine polypharmacology: Cancer therapy through modulatingthe tumor microenvironment and oxylipin dynamics. Pharmacol Therapeut 162, 58-68.

4. Gunasekaran T, Haile T, Nigusse T, Dhanaraju DM (2014) Nanotechnology: an effective tool for enhancing bioavailability and bioactivity of phytomedicine. Asian Pac J Trop Biomed 4, 1-7.

5. Farzaei, H. M., Shahpiri, Z., Bahramsoltani, R., Moghaddam, M., Najafi, F., Rahimi R (2017) Efficacy and Tolerability of Phytomedicines in Multiple Sclerosis Patients: A Review. CNS Drugs 31, 867-889.

6. Norrby M. Madej A. Ekstedt E, Holm L (2013) Effects of genistein on oestrogen and progesterone receptor, proliferative marker $\mathrm{Ki}-67$ and carbonic anhydrase localisation in the uterus and cervix of gilts after insemination. Anim Reprod Sci 138, 90-101.

7. Kašparová M (2013) Phytoestrogens from red clover. Prakt lékáren 9, 201-203.

8. Rajput SM, Sarkar DP (2017) Modulation of neuro-inflammatory condition, acetylcholinesterase and antioxidant levels by genistein attenuates diabetes associated cognitive decline in mice. Chem Biol Interact 268, 93-102. 
9. Sarasquete C, Manzanaro UM, Ortiz-Delgado BJ (2018) Toxicity and non-harmful effects of the soya isoflavones, genistein and daidzein, in embryos of the zebrafish, Danio rerio. Comp Biochem Physiol C Toxicol Pharmacol, 57-67.

10. Basu P, Maier C (2018) Phytoestrogens and breast cancer: In vitro anticancer activities of isoflavones, lignans, coumestans, stilbenes and their analogs and derivatives. Biomed Pharmacother $107,1648-1666$.

11. Liu X, Sun C, Jin X, Li P, Ye F, Zhao T, Gong L, Li Q (2013) Genistein enhances the radio-sensitivity of breast cancer via G (2)/M cell cycle arrest and apoptosis. Molecules 18, 13200-13217.

12. Sandhua VK, Demiray YE, Yanagawa Y, Stork, O (2020) Dietary phytoestrogens modulate aggression and activity in social behavior circuits of male mice. Horm Behav 119, 104637.

13. Pan W, Ikeda K, Takebe M, Yamori Y (2001) Genistein, Daidzein and glycitein inhibit growth and DNA synthesis of aortic smooth muscle cells from stroke-prone spontaneously hypertensive rats. J Nutr $131,1154-1158$.

14. Hu H, Li H (2018) Prunetin inhibits lipopolysaccharide-induced inflammatory cytokine production and MUC5AC expression by inactivating the TLR4/MyD88 pathway in human nasal epithelial cells. Biomed Pharmacother 106, 1469-1477.

15. Yang G, Ham I, Choi YH (2013) Anti-inflammatory effect of prunetin via the suppression of NF-kB pathway. Food Chem Toxicol 58, 124-132.

16. Chen C, Wang Y, Chen S, Ruan X, Liao H, Zhang Y, Sun J, Gao J, Deng G (2020) Genistein inhibits migration and invasion of cervical cancer HeLa cellsby regulating FAK-paxillin and MAPK signaling pathways. Taiwan J Obstet Gyne 59, 403-408.

17. Mosmann T (1983) Rapid colorimetric assay for cellular growth and survival: application to proliferation and cytotoxicity assays. J Immunol Methods 65, 55-63.

18. Zhang J, Liu L, Wang J, Ren B, Zhang L, Li W (2018) Formononetin, an isoflavone from Astragalus membranaceus inhibits proliferation and metastasis of ovarian cancer cells. Journal of Ethnopharmacology 221, 91-99.

19. Nalbantsoy A, Nesil T, Yılmaz-Dilsiz Ö, Aksu G, Khan S, Bedir E (2012) Evaluation of the immunomodulatory properties in mice and in vitro anti-inflammatory activity of cycloartane type saponins from Astragalus species. J Ethnopharmacol 139, 574-581.

20. Feng-Ying Z, Shun-Xing, L, Lu-Xiu L (2007) Assessment of bioavailability and risk of iron in phytomedicinesAconitum carmichaeliand Paeonia lactiflora. J Trace Elem Med Bio 21, 77-83.

21. Militao GC, Pinheiro SM, Dantas IN, PessoaC, de Moraes MO, Costa-Lotufo LC, Lima, MA, Silveira, ER (2007) Bioassay-guided fractionation of ptero-carpans from roots of Harpalyce brasiliana Benth. Bioorg Med Chem 15, 6687-6691.

22. Szliszka E, Czuba PZ, Mertas A, Paradysz A, Krol W (2013) The dietary isoflavone biochanin-A sensitizes prostate cancer cells toTRAIL-induced apoptosis. Urol Oncol 31, 331-342.

23. Kuete V, Sandjo PL, Kwamou NMG. Wiench B, Nkengfack EA, Efferth T (2014) Activity of three cytotoxic isoflavonoids from Erythrina excelsa and Erythrina senegalensis (neobavaisoflavone, 
sigmoidin $\mathrm{H}$ andisoneorautenol) toward multi-factorial drug resistant cancer cells. Phytomedicine 21, 682-688.

24. Yan Y, Chai ZC, Wang WD, Wu J, Xiao HH, Hou XL, Zhu ND, Yu Y (2014) Simultaneous determination of puerarin, daidzin, daidzein, paeoniflorin, albiflorin, liquiritin and liquiritigenin in rat plasma and its application to a pharmacokinetic study of Ge-Gen Decoction by aliquid chromatographyelectrospray ionization-tandem massspectrometry. J Pharm Biomed Anal 95, 76-84.

25. Alkhamaiseh IS, Aljofan M (2020) Prevalence of use and reported side effects of herbal medicine among adultsin Saudi Arabia. Complement Ther Med 48, 102255.

26. Sarfraz A, Javeed M, Shah AM, Hussain G, Shafiq N, Sarfraz I, Riaz A, Sadiqa A, Zara R, Zafar S, Kanwal L, Sarker DS, Rasul A (2020) Biochanin A: A novel bioactive multifunctional compound from nature. Sci Total Environ 722, 137907.

27. Ma HC, Zhang XY, Tang HL, Yang JX, Cui MW, Han CC, Ji YW (2018) MicroRNA-1469, a p53responsive microRNA promotes Genistein induced T apoptosis by targeting Mcl1 in human laryngeal cancer cells. Biomed Pharmacother 106, 665-671.

28. Po LS, Wang TT, Chen ZY, Leung LK (2002) Genistein-induced apoptosis in MCF-7 cells involves changes in Bak andBcl-x without evidence of anti-oestrogenic effects. $\mathrm{Br} J$ Nutr Title 88, 463-469.

29. Wang X, Clubbs EA, Bomser JA (2006) Genistein modulates prostateepithelial cell proliferation via estrogen- and extracellular signal-regulatedkinase-dependent pathways. J Nutr Biochem 17, 2042410.

30. Choi JE, Kim T, Lee SM (2007) Pro-apoptotic effect and cytotoxicity of genistein and genistin in humanovarian cancer SK-OV-3 cells. Life Sci 80, 1403-1408.

31. Hsu NY, Shyu WH, Hu WT, Yeh PJ, Lin WY, Lee YL, Yeh TY, Dai YH, Perng SD, Su HS, Huang HY, Su JS (2018) Anti-proliferative activity of biochanin A in human osteosarcoma cells viamitochondrialinvolved apoptosis. Food Chem Toxicol 112, 194-204.

32. Sallama AAA, Allam, MR (2021) Promising targets of chrysin and daidzein in colorectal cancer: Amphiregulin, CXCL1, and MMP-9. Eur J Pharmacol 892, 173763.

33. Maphanaoa P, Thanana R, Loilome W, Chio-Srichan S. Wongwattanakul M, Sakonsinsiri C (2020) Synchrotron FTIR microspectroscopy revealed apoptosis-induced biomolecular changes of cholangiocarcinoma cells treated with ursolic acid. Biochim Biophys Acta Gen Subj 1864, 129708.

34. Constantinou Al, Kamath N, Murley JS (1998) Genistein Inactivates bcl-2, Delays the G2/M Phase of the Cell Cycle, and Induces Apoptosis of Human Breast Adenocarcinoma MCF-7 Cells. Eur J Cancer 34, 1927-1934.

35. Bi YL, Min MS, Yan LW (2018) Genistein induced anticancer effects on pancreatic cancer cell lines involves mitochondrial apoptosis, G0/G1 cell cycle arrest and regulation of STAT3 signalling pathway. Phytomedicine 39, 10-16.

36. Wang B, Xu H, Hu X, Ma W, Zhang J, Li Y, Yu M, Zhang Y, Li X, Ye X (2020) Synergetic inhibition of daidzein and regular exercise on breast cancer in bearing-4T1 mice by regulating NK cells and apoptosis pathway. Life Sci 245, 117387. 
37. Idriss HT, Naismith JH (2000) TNF alpha and the TNF receptor superfamily: structure-function relationship(s). Microsc Res Tech 50, 84-95.

38. Hayashi T, Yamada K, Esaki T, Kuzuya M, Satake S, Ishikawa T, Hiaka H, Iguchi A (1995) Estrogen increases endothelial nitricoxide by a receptor mediated system. Biochemical and Biophysical Research Communications 214, 847-55.

39. You HJ, Kim JY, Jeong GH (2003) 17b-Estradiol increases induciblenitric oxide synthase expression in macrophages. Biochem Biophys Res Commun 303, 1129-1134.

40. Sharma A, Joshi R, Kumar S, Sharma R, Rajneesh, Padwad Y, Gupta M (2018) Prunus cerasoides fruit extract ameliorates inflammatory stress by modulation of iNOS pathway and Th1/ Th2 immune homeostasis in activated murine macrophages and lymphocytes. Inflammopharmacology 26, 14831495.

41. Nakaya $M$, Tachibana $H$, Yamada $K$ (2005) Isoflavone genistein and daidzein up-regulate LPSinducedinducible nitric oxide synthase activity through estrogenreceptor pathway in RAW264.7 cells. Biochem Pharmacol 71, 108-114.

\section{Tables}

Table 1. Gene-specific primer sequences used in RT-PCR

\begin{tabular}{|c|c|c|}
\hline Genes & Primer & Primer Sequence \\
\hline \multirow[t]{2}{*}{ CASP-3 } & $\mathrm{F}$ & 5'-CTCGGTCTGGTACAGATGTCGA-3 \\
\hline & $\mathrm{R}$ & 5'-CATGGCTCAGAAGCACACAAAC-3' \\
\hline \multirow[t]{2}{*}{$T N F-a$} & $\mathrm{~F}$ & 5'-GAAAGCATGATCCGGGACGTG-3' \\
\hline & $\mathrm{R}$ & 5'-GATGGCAGAGAGGAGGTTGAC-3' \\
\hline \multirow[t]{2}{*}{$\beta$-actin } & $\mathrm{F}$ & 5'- AAATCTGGCACCACACCTTC -3' \\
\hline & $\mathrm{R}$ & 5'- GGGGTGTTGAAGGTCTCAAA -3' \\
\hline
\end{tabular}

Table 2. $\mathrm{IC}_{50}$ values of prunetin and doxorubicin for cell lines exposed to different concentrations 


\begin{tabular}{|lll|}
\hline Cell lines & Prunetin $\mu \mathrm{g} / \mathrm{mL}$ & Doxorubicin $\mu \mathrm{g} / \mathrm{mL}$ \\
\hline MDA-MB 231 & $32.11 \pm 0.63$ & $10.11 \pm 0.21$ \\
\hline HeLa & $39.75 \pm 0.05$ & $1.49 \pm 0.08$ \\
\hline A-549 & $28.20 \pm 0.03$ & $14.19 \pm 0.16$ \\
\hline PC3 & $31.75 \pm 0.01$ & $21.10 \pm 0.04$ \\
\hline RT-4 & $21.11 \pm 0.05$ & $1.10 \pm 0.02$ \\
\hline HEK-293 & $30.03 \pm 0.02$ & $2.86 \pm 0.01$ \\
\hline Caco-2 & $24.16 \pm 0.12$ & $1.05 \pm 0.06$ \\
\hline MCF-7 & $27.18 \pm 0.32$ & $1.25 \pm 0.02$ \\
\hline
\end{tabular}

Table 3. iNOS and MTT test results of prunetin and Doxorubicin

\begin{tabular}{|lll|}
\hline & \multicolumn{2}{l|}{ RAW 264.7 (ug/mL) } \\
\hline & iNOS IC $_{50}$ & MTT IC $_{50}$ \\
\hline Prunetin & $5.18 \pm 0.15$ & $>50$ \\
\hline Doxorubicine & $6.26 \pm 2.16$ & $>50$ \\
\hline
\end{tabular}

Figures 


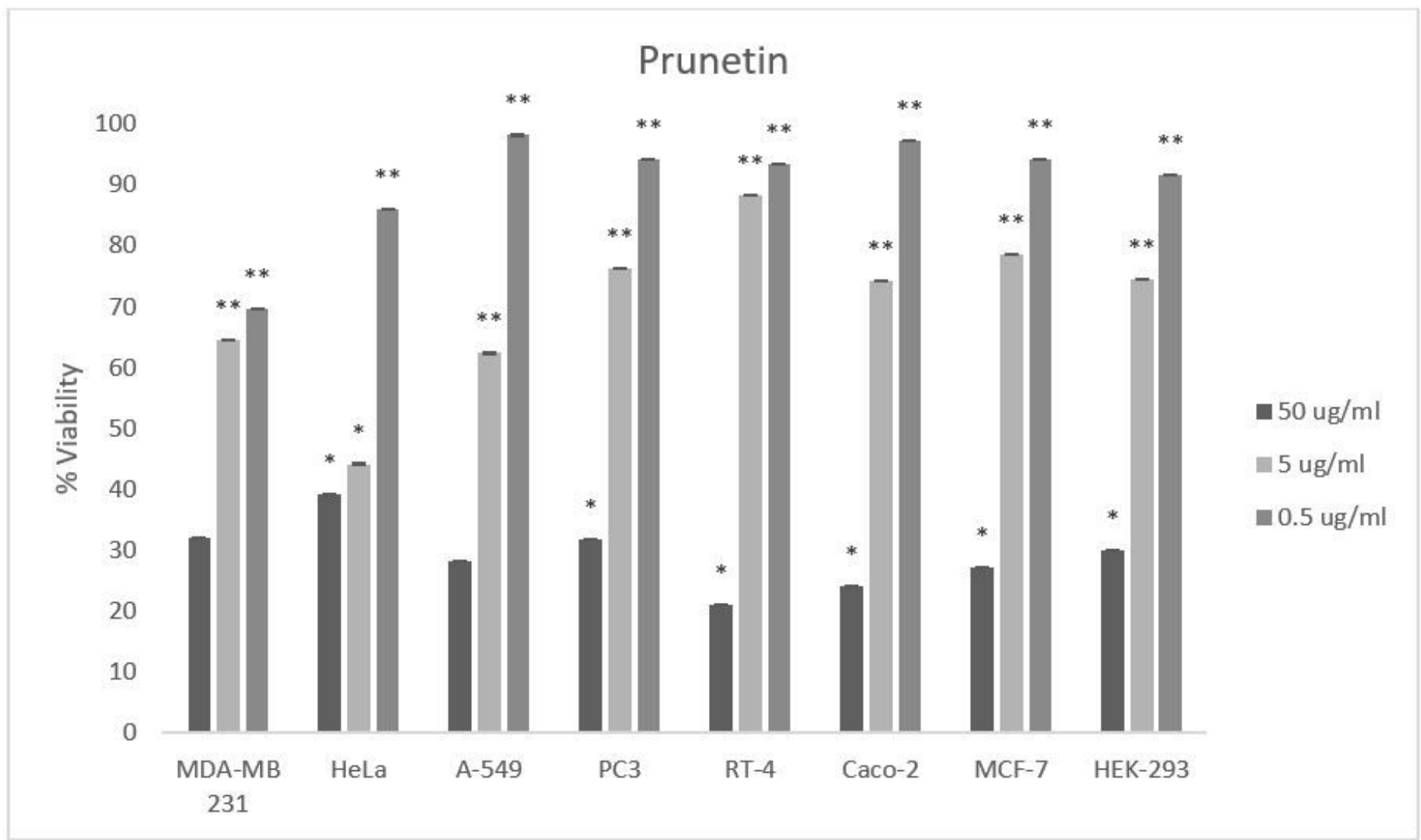

Figure 1

Effects of prunetin on the viability of cancer and healthy cells in comparison with the control (100\% viability). Mean \pm standard deviation of three independent experiment is indicated by each bar. Significant differences $(p<0.5$ and $p<0.05)$ were marked with "*" and "**" respectively. 
A
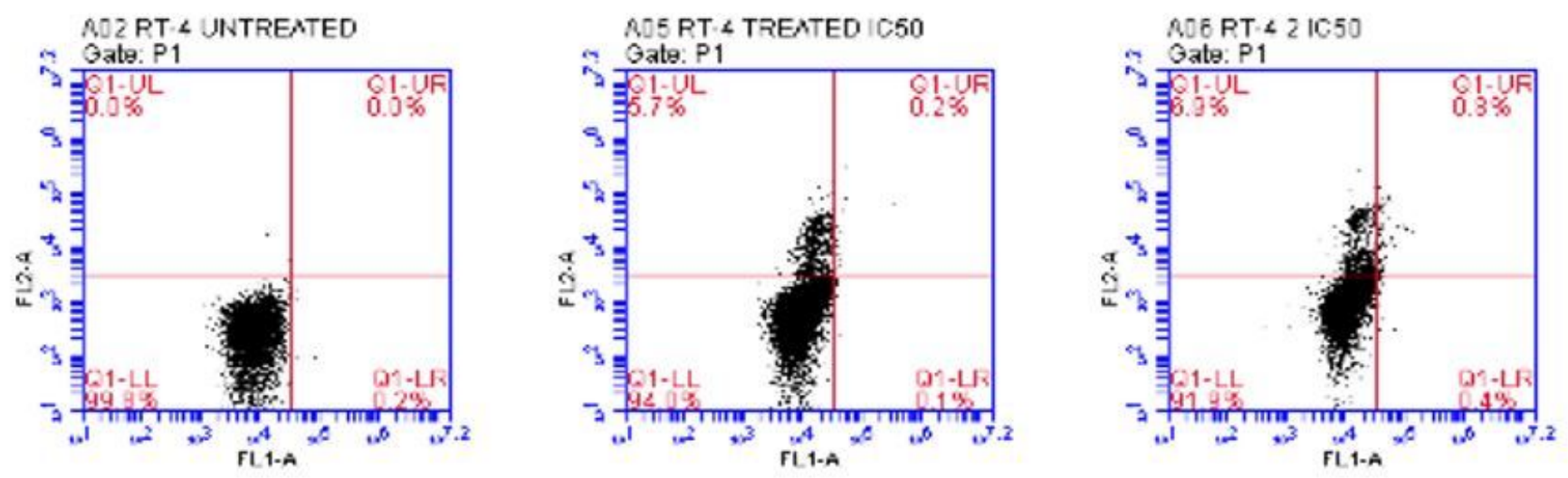

\section{B}
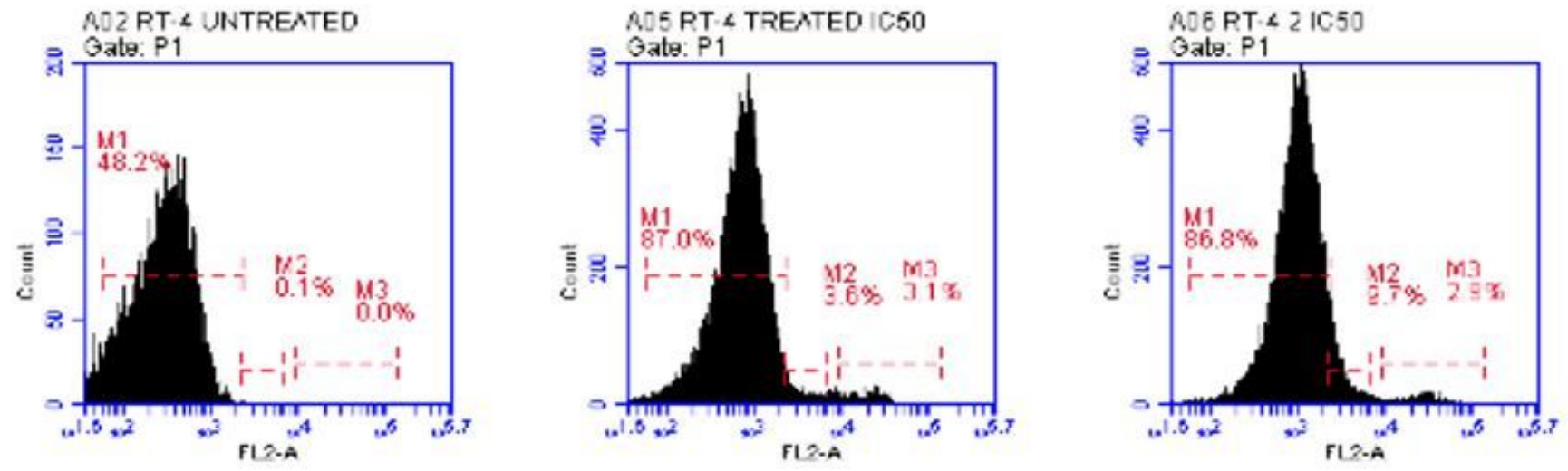

Figure 2

Flow cytometric analyses of RT-4 cells with Annexin V-FITC (A) and PI (B) double staining showed slightly increased apoptotic population following prunetin treatment. All data are expressed as the mean \pm SD of three independent experiments. 
A
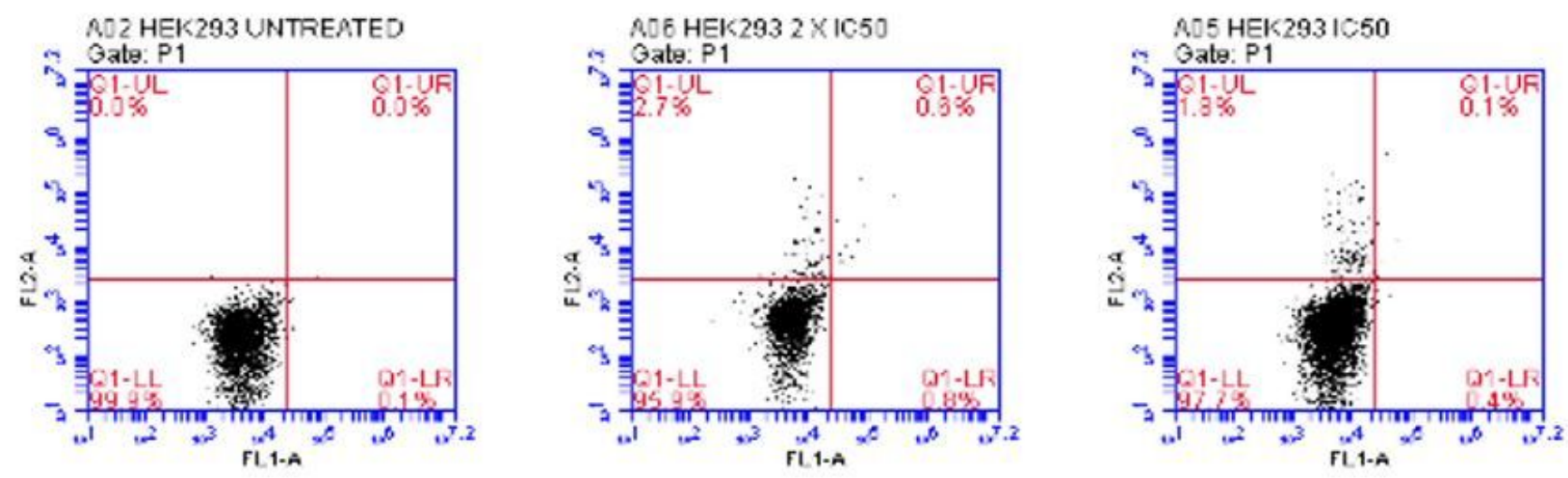

\section{B}
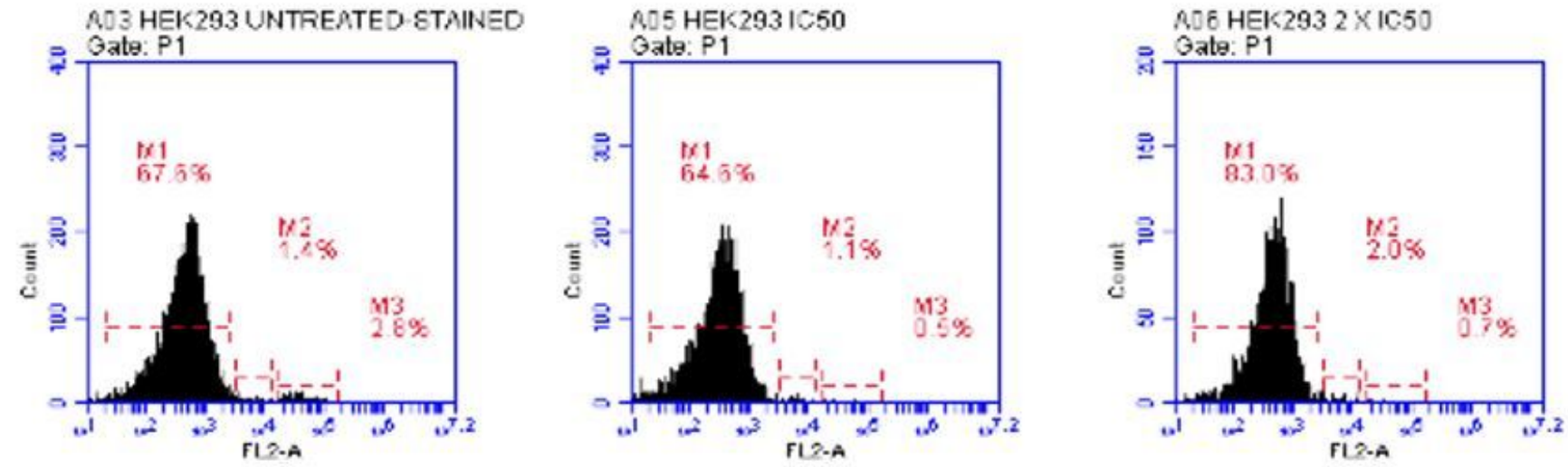

\section{Figure 3}

Flow cytometric analyses of HEK-293 cells with Annexin V-FITC (A) and PI (B) double staining showed no apoptotic population following prunetin treatment. All data are expressed as the mean \pm SD of three independent experiments. 


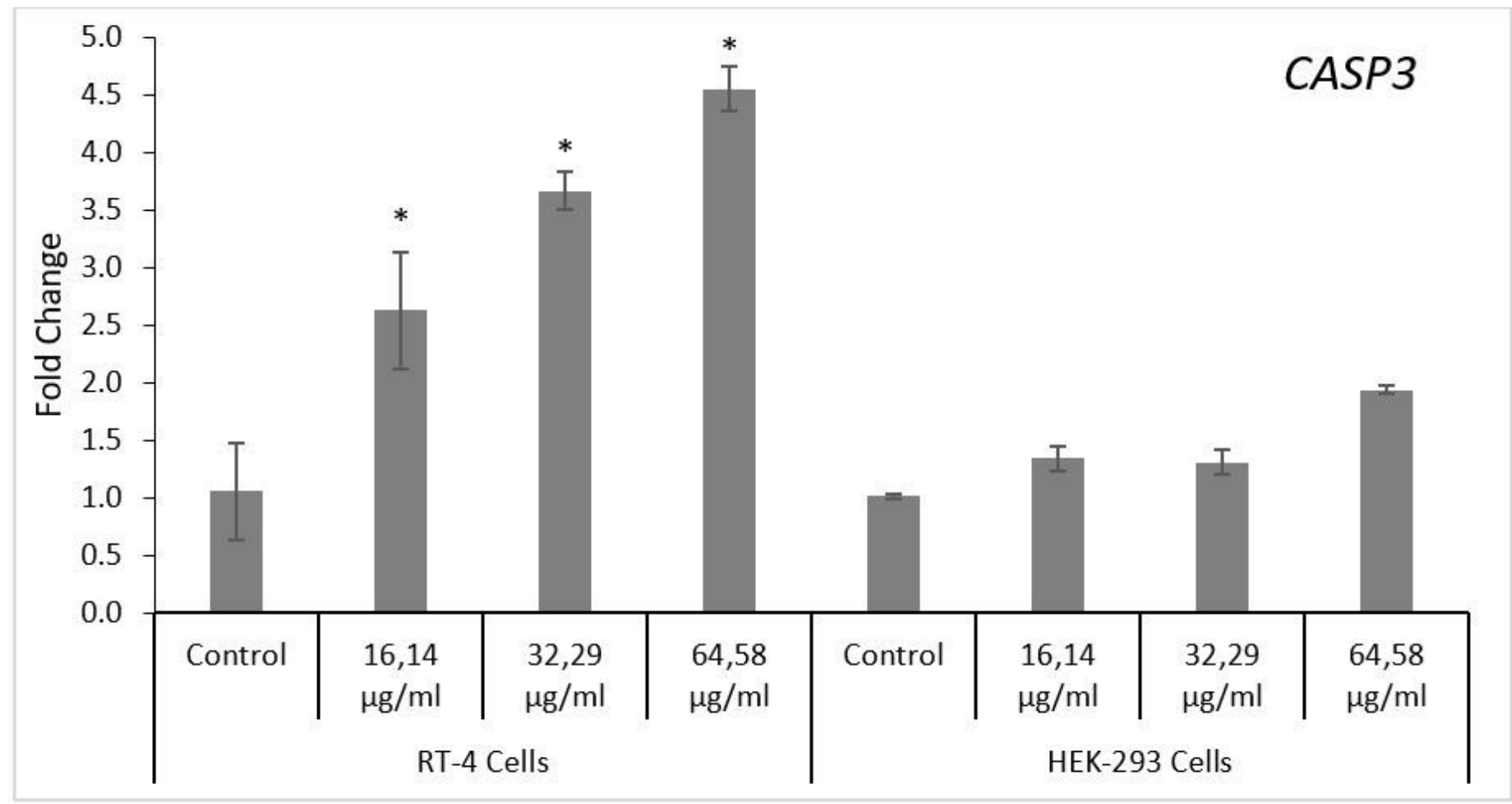

\section{Figure 4}

Realtime-PCR analysis of CASP3 gene expression. Relative mRNA levels of the CASP3 gene following 0$48 \mathrm{~h}$ treatment with prunetin in RT-4 and HEK-293 cells. Prunetin induces apoptosis through caspase 3 activation in RT-4 cell as compared with the control group (untreated cells) and HEK-293 cells. The data are mean \pm SD of three independent experiments $\left({ }^{*} \mathrm{p}<0.05\right)$. 


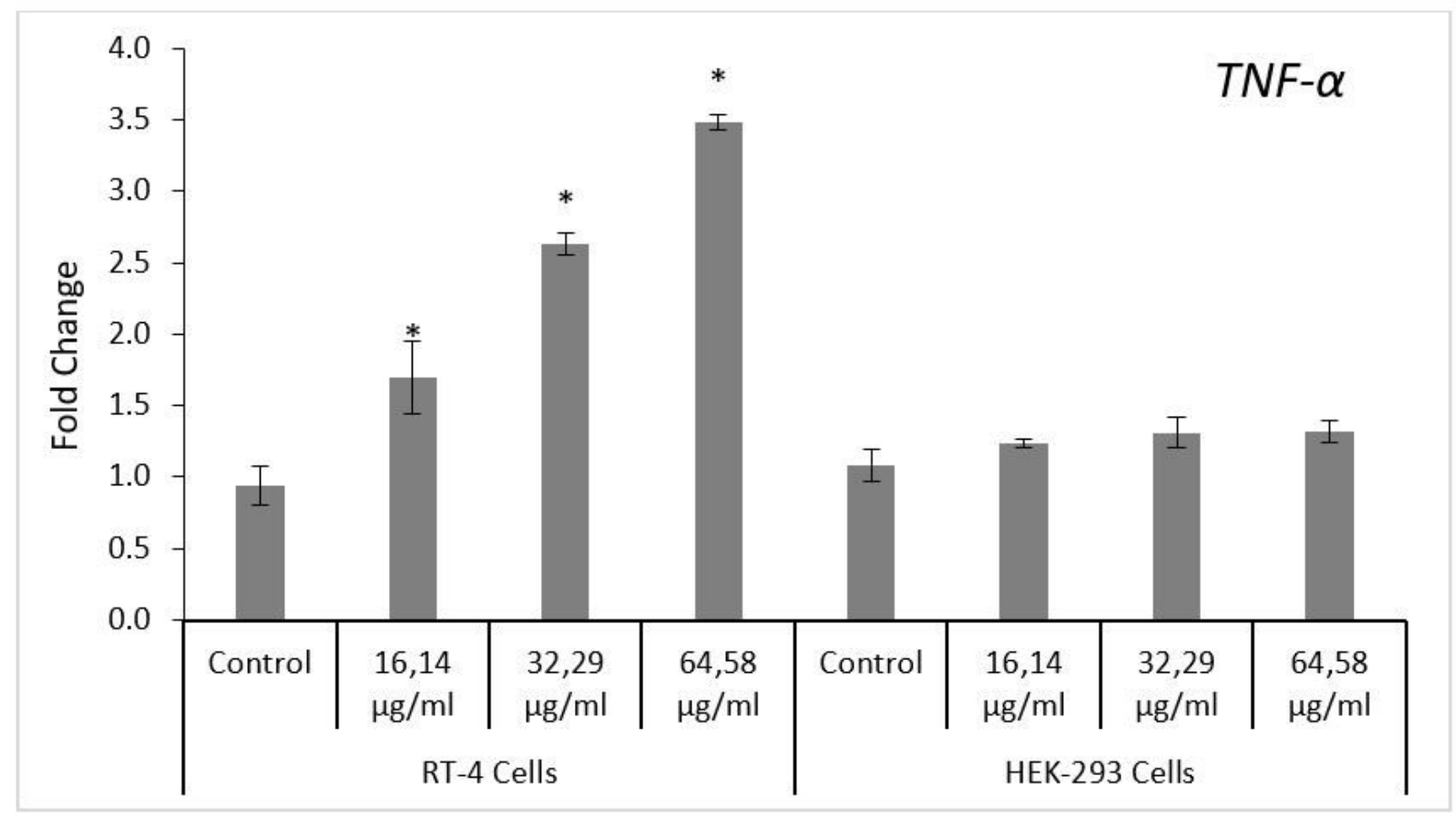

Figure 5

Realtime-PCR analysis of TNF-a gene expression. Relative mRNA levels of the TNF- a gene following 0$48 \mathrm{~h}$ treatment with prunetin in RT-4 and HEK-293 cells. Prunetin induces apoptosis through TNF- $\mathrm{a}$ activation in RT-4 cell as compared with the control group (untreated cells) and HEK-293 cells. The represented data were mean \pm SD of three independent experiments $\left({ }^{*} p<0.05\right)$. 


\section{RAW 264.7}

120

100

80

60

40

20

0

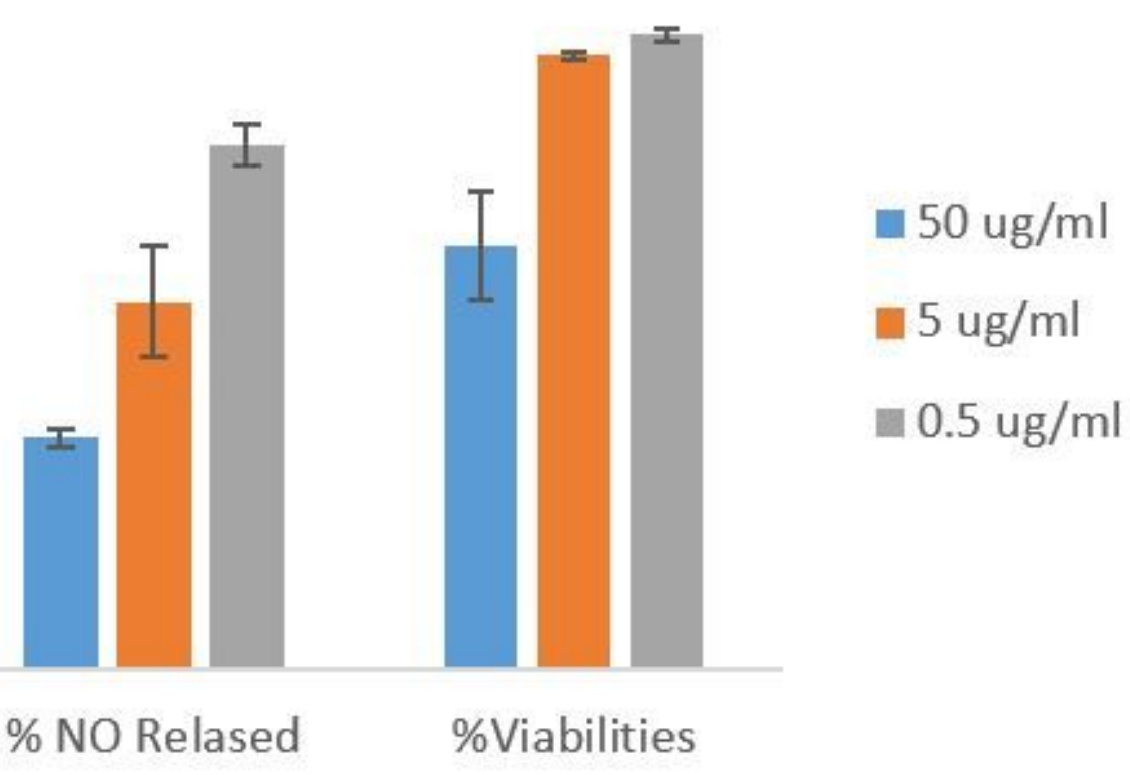

Figure 6

iNOS inhibition, NO and viability of prunetin on RAW 264.7 macrophage cell

\section{Supplementary Files}

This is a list of supplementary files associated with this preprint. Click to download.

- GrapAbs.jpg 